Jean-Claude Alvarez*, Pierre Moine, Isabelle Etting, Djillali Annane and Islam Amine Larabi

\title{
Quantification of plasma remdesivir and its metabolite GS-441524 using liquid chromatography coupled to tandem mass spectrometry. Application to a Covid-19 treated patient
}

https://doi.org/10.1515/cclm-2020-0612

Received April 28, 2020; accepted May 18, 2020; published online June 23, 2020

\section{Abstract}

Objectives: A method based on liquid chromatography coupled to triple quadrupole mass spectrometry detection using $50 \mu \mathrm{L}$ of plasma was developed and fully validated for quantification of remdesivir and its active metabolites GS-441524.

Methods: A simple protein precipitation was carried out using $75 \mu \mathrm{L}$ of methanol containing the internal standard (IS) remdesivir- ${ }^{13} \mathrm{C}^{6}$ and $5 \mu \mathrm{L} \mathrm{ZnSO} 41 \mathrm{M}$. After separation on Kinetex $^{\circledR} 2.6 \mu \mathrm{m}$ Polar C18 100A LC column $(100 \times 2.1 \mathrm{~mm}$ i.d.), both compounds were detected by a mass spectrometer with electrospray ionization in positive mode. The ion transitions used were $\mathrm{m} / z 603.3 \rightarrow \mathrm{m} / z 200.0$ and $\mathrm{m} / \mathrm{z} 229.0$ for remdesivir, $\mathrm{m} / z 292.2 \rightarrow \mathrm{m} / z 173.1$ and $\mathrm{m} / z 147.1$ for GS441524 and $m / z 609.3 \rightarrow m / z 206.0$ for remdesivir ${ }^{13} \mathrm{C}^{6}$.

Results: Calibration curves were linear in the $1-5000 \mu \mathrm{g} / \mathrm{L}$ range for remdesivir and 5-2500 for GS-441524, with limit of detection set at 0.5 and $2 \mu \mathrm{g} / \mathrm{L}$ and limit of quantification at 1 and $5 \mu \mathrm{g} / \mathrm{L}$, respectively. Precisions evaluated at 2.5, 400 and $4000 \mu \mathrm{g} / \mathrm{L}$ for remdesivir and 12.5, 125, $2000 \mu \mathrm{g} / \mathrm{L}$ for GS441524 were lower than $14.7 \%$ and accuracy was in the [89.6110.2\%] range. A slight matrix effect was observed,

\footnotetext{
*Corresponding author: Professor Jean Claude Alvarez, Laboratoire de Pharmacologie-Toxicologie, Université de Versailles Saint-Quentin en Yvelines, Inserm U-1173, Hôpital Raymond Poincaré, AP-HP, 104, Boulevard R. Poincaré, 92380, Garches, France, Tel: +3314710 79 46; Fax: 331471079 23, E-mail: jean-claude.alvarez@aphp.fr Pierre Moine and Djillali Annane: Intensive Care Unit, Paris-Saclay University (Versailles Saint-Quentin-en-Yvelines), Inserm U-1173, Raymond Poincaré Hospital, AP-HP, Garches, France

Isabelle Etting and Islam Amine Larabi: Department of Pharmacology and Toxicology, Paris-Saclay University (Versailles Saint-Quentin-enYvelines), Inserm U-1173, Raymond Poincaré Hospital, AP-HP, Garches, France
}

compensated by IS. Higher stability of remdesivir and metabolite was observed on NaF-plasma. After 200 mg IV single administration, remdesivir concentration decrease rapidly with a half-life less than $1 \mathrm{~h}$ while GS-441524 appeared rapidly and decreased slowly until $\mathrm{H}_{24}$ with a half-life around $12 \mathrm{~h}$.

Conclusions: This method would be useful for therapeutic drug monitoring of these compounds in Covid-19 pandemic.

Keywords: Covid-19; GS-441524; LC-MS/MS; remdesivir.

\section{Introduction}

The current pandemic coronavirus disease 2019 (Covid-19) has developed interest in developing treatment in order to decrease impact on human life [1]. Many pharmacologic treatments have been proposed against the severe acute respiratory syndrome coronarovirus 2 (SARS-CoV-2) in cause in this pandemic [2]. There are currently no approved effective therapeutic agents available for the treatment of Covid19. The most promising therapy appeared to be remdesivir [2].

Remdesivir (GS-5734) is a broad-spectrum small molecule antiviral drug that has demonstrated activity against RNA viruses in different families. Its therapeutic efficacy has been primary found against Ebola virus in rhesus monkey [3]. It has been found to have superior antiviral activity to lopinavir and ritonavir in vitro against Middle East respiratory coronavirus (MERS-CoV), a precedent coronarovirus disease [4]. In vitro, it inhibits SARSCoV-2 virus replication in Vero E6 cells with an estimated $50 \%$ effective concentration $\left(\mathrm{EC}_{50}\right)$ around $13.8 \mathrm{mg} / \mathrm{L}$. This concentration is decreased to less than $3.5 \mathrm{mg} / \mathrm{L}$ in association with emetine, another antiviral compound [5]. Wang et al. (2020) has shown $\mathrm{EC}_{50}$ much lower on the same type of cell (Vero cells) with values around $0.4 \mathrm{mg} / \mathrm{L}$ [6]. However, remdesivir is a prodrug of a parent adenosine analog, called GS-441524, both of which being metabolized in human cell into an active nucleoside triphosphate [7]. 
GS-441524 is the major circulating metabolite of remdesivir. No $\mathrm{EC}_{50}$ has been published for GS-441524 on SARS-CoV-2 virus, but this metabolite appeared to be more potent than the parent drug. When activated, both seem to inhibit RNA-dependent RNA polymerase from coronavirus, targeting the viral genome replication process $[8,9]$.

Until now, remdesivir treatment is not European Medicines Agency (EMA) approved, but has been recently approved by US Food and Drug Administration (FDA). It is still being tested in ongoing randomized trials or in compassionate use for patients with severe Covid-19 [10, 11].

Few data are available on pharmacokinetics (PK) of remdesivir and its metabolite in humans. Only those from the report on "Summary on compassionate use" released by Gilead, the pharmaceutic company which markets this product were found [12]. Due to an intensive hepatic metabolism, remdesivir being a substrate for cytochrome P450 2C8 (CYP2C8), CYP2D6, and CYP 3A4, which would likely result in almost complete first-pass clearance, this drug is considered as not suitable for oral administration. Consequently, only IV route is actually available for remdesivir. Despite remdesivir is a substrate for different CYP, its main metabolism in humans after IV administration is likely to be predominantly mediated by hydrolase activity [12]. Elimination is predominantly in urine $(74 \%)$, the predominant form being GS-441524 (49\%) followed by remdesivir $(10 \%)$ and other metabolites not currently clearly identified.

After 3 to $225 \mathrm{mg}$ single-dose IV infusion over $2 \mathrm{~h}$ in humans, it has been shown that remdesivir and GS-441524 presented a linear PK profile. After a 150 and $225 \mathrm{mg} 2 \mathrm{~h}$ IV infusion in eight healthy human subjects, remdesivir peak plasma concentration $\left(\mathrm{C}_{\max }\right)$ observed at the end of infusion were $2280 \mu \mathrm{g} / \mathrm{L}(\mathrm{CV} 30.1 \%$ ) and $4421.3 \mu \mathrm{g} / \mathrm{L}(\mathrm{CV}$ $16.0 \%$ ), respectively. Half-life was approximately $1 \mathrm{~h}$, this short value leading to a non-accumulation following multiple once-daily administrations [12]. After this kind of chronic administration, GS-441524 reached steady-state by day four, and accumulated around 2-fold compared to single administration, in accordance with its longer half-life, around $24 \mathrm{~h} \mathrm{[12].} \mathrm{C}_{\max }$ for the metabolite was measured at $152 \mu \mathrm{g} / \mathrm{L}$ on day one following $30 \mathrm{~min} \mathrm{IV}$ infusion of $200 \mathrm{mg}$ loading-doses, and $142 \mu \mathrm{g} / \mathrm{L}$ on day five following a $200 \mathrm{mg}$ loading-dose on day 1 and $100 \mathrm{mg}$ daily for four days [12].

For the treatment of Covid-19, in order to target exposures of the virus in plasma and in cells, the selected regimen proposed by Gilead ${ }^{\circledR}$ is $200 \mathrm{mg}$ loading IV dose on day one followed by nine days of $100 \mathrm{mg}$ once-daily [12]. Studies of the pharmacokinetic/pharmacodynamics relationship of remdesivir and its metabolite appeared necessary in the context of Covid-19. Moreover, there is no data available on the pharmacokinetics of remdesivir in patients with renal or hepatic impairment, which are frequent in Covid-19. As remdesivir appeared to be rapidly cleaved by hydrolases, the effect of hepatic impairment on its plasma levels is probably low, but no data are available for the metabolism of its active metabolite. In patients with impaired renal function, even if remdesivir is not cleared unchanged in urine to any substantial extent, its metabolite GS-441524 is found in great amount in urine and its plasma concentration may theoretically increase.

Despite these study needs, to our knowledge, no method of quantification of remdesivir and its metabolite in plasma is available. The purpose of this study was to develop and validate a liquid chromatography coupled to tandem mass spectrometry (LC-MS/MS) method, and to applied it to a Covid-19 treated patient after the first loading-dose administration. Since esterases are present in great quantity in whole blood, stability of remdesivir and that of its metabolite were also investigated in two different sampling tubes and in different storages conditions.

\section{Materials and methods}

\section{Chemicals and reagents}

The reference standards of remdesivir (Figure $1 \mathrm{~A}, \mathrm{C}_{27} \mathrm{H}_{35} \mathrm{~N}_{6} \mathrm{O}_{8} \mathrm{P}, \mathrm{MW}$ : $602.6 \mathrm{~g} / \mathrm{mol}$, purity 99.6\%), GS-441524 (Figure $1 \mathrm{~B}, \mathrm{C}_{12} \mathrm{H}_{13} \mathrm{~N}_{5} \mathrm{O}_{4}$, MW: $291.3 \mathrm{~g} / \mathrm{mol}$, purity $98.6 \%$ ) and remdesivir ${ }^{13} \mathrm{C}_{6}$, used as internal standard (IS) were purchased from Alsachim (Illkirch, France). Formic acid and methanol were high-performance liquid chromatography (HPLC) grade while acetonitrile was mass spectrometry (LC/MS) grade and were obtained from Merck (Saint-Quentin Fallavier, France). Zinc sulfate $\left(\mathrm{ZnSO}_{4}\right)$ was obtained from Prolabo (Paris, France) and prepared at a concentration of $1 \mathrm{M}$ in ultra-pure water $(18 \mathrm{M} \Omega)$ obtained by ultrafiltration with a Q-Pod (Millipore Corp., Molsheim, France). Formate buffer containing $10 \mathrm{mM}$ ammonium formate in $0.1 \%$ formic acid was prepared in ultra-pure water and stored after each analysis at $+4^{\circ} \mathrm{C}$ for a maximum of one week. Blank plasma was obtained from the Etablissement Français du Sang (EFS, La Plaine Saint-Denis, France).

Li-heparin and NaF-containing tubes used in the stability study were obtained from Becton Dickinson (Rungis, France). Drug-free human blood for this study was obtained from five healthy volunteers (one man and four women) from the laboratory who are not medically treated.

\section{Working solutions, calibration standards and quality controls}

Stock solutions of remdesivir, remdesivir- ${ }^{13} \mathrm{C}_{6}$ and GS-441524 were prepared in methanol at a concentration of $1 \mathrm{mg} / \mathrm{mL}$. Working solutions for calibration standards (CS) were obtained by dilution of the stock solution of remdesivir and GS-441524 in methanol to obtain solutions at 10, $1,0.1$, and $0.01 \mu \mathrm{g} / \mathrm{mL}$ for remdesivir and five times more concentrated 
<smiles>CCC(CC)COC(=O)C(C)NP(=O)(OCC1O[C@@](C#N)(c2ccc3c(N)ncnn23)[C@H](O)[C@@H]1O)Oc1ccccc1</smiles>

(A) Remdesivir<smiles>N#C[C@]1(c2ccc3c(N)ncnn23)OC(CO)[C@@H](O)[C@@H]1O</smiles>

(B) GS-441524
Figure 1: Remdesivir and GS-441524 chemical structures. for the metabolite. Working solution for quality control (QC) preparation was also prepared at the same concentrations by dilution in methanol of another $1 \mathrm{mg} / \mathrm{mL}$ stock solution prepared separately. IS was diluted in methanol to obtain a working solution at $0.2 \mu \mathrm{g} / \mathrm{mL}$.

CS used for calibration curve were prepared each day by spiking with appropriate volumes of the previously mentioned working solutions in $50 \mu \mathrm{L}$ blank plasma in order to obtain the following concentrations: $1,5,10,25,50,100,250,500,1000$, and $5000 \mu \mathrm{g} / \mathrm{L}$ for remdesivir, and 5, 25, 50, 125, 250, 500, 1250, and $2500 \mu \mathrm{g} / \mathrm{L}$ for GS-441524, with a zero CS.

QC samples were prepared in bulk in blank plasma at concentrations of 1.0 (lower limit of quantification, (LLOQ)), 2.5, 400 and $4000 \mu \mathrm{g} / \mathrm{L}$ for remdesivir and 5.0 (LLOQ), 12.5, 125, $2000 \mu \mathrm{g} / \mathrm{L}$. Stock and working solutions and plasma QCs were stored at $-20{ }^{\circ} \mathrm{C}$.

\section{Sample preparation}

Fifty $\mu \mathrm{L}$ of plasma were precipitated with $75 \mu \mathrm{L}$ methanol containing IS and $5 \mu \mathrm{L}$ of $\mathrm{ZnSO}_{4} 1 \mathrm{M}$. After vortex mix for $15 \mathrm{~s}$, samples were left at $+4^{\circ} \mathrm{C}$ for $10 \mathrm{~min}$, and then centrifuged (10 min, $18000 \mathrm{~g}$ ). Supernatant was transferred into injection vials for analysis (injection volume $20 \mu \mathrm{L}$ ).

\section{LC-MS/MS system and conditions}

Chromatography was performed on a Dionex Ultimate 3000 pump (ThermoFisher, Les Ulis, France) using a Kinetex ${ }^{\circledR} 2.6 \mu \mathrm{m}$ Polar C18 100A LC column $(100 \times 2.1 \mathrm{~mm}$ i.d. $)$ (Phenomenex, Le Pecq, France) preheated at $30{ }^{\circ} \mathrm{C}$. The elution was performed with a gradient of $10 \mathrm{mM}$ sodium formate buffer in $0.1 \%$ formic acid (A) and acetonitrile (B) starting from $0 \%$ of (B) to $100 \%$ in $2 \mathrm{~min}$, and hold for $1 \mathrm{~min}$ to $100 \%$. The equilibration time between two consecutive runs was set at $2 \mathrm{~min}$. The total run time was $5 \mathrm{~min}$. The mobile phase was used at a constant flow rate of $0.5 \mathrm{~mL} / \mathrm{min}$. Compounds were detected by a TSQ Endura triple-quadrupole mass spectrometer (ThermoFisher) equipped with an electrospray ionization (ESI) source set in a positive mode with ion spray potential at $+3.5 \mathrm{kV}$. Capillary temperature was set at $350{ }^{\circ} \mathrm{C}$. Nitrogen (Nitrox UHPLCMS 18, nitrogen generator; Domnick Hunter, Villefranche sur Saone, France) was employed as sheath gas at 35 arbitrary pressure unit. The argon gas collisioninduced dissociation was used with a pressure of $1.5 \mathrm{mTorr}$. Data were collected in multiple reactions monitoring (MRM) mode. The ion transitions (and corresponding collision energies) used to monitor compounds were $m / z 603.3 \rightarrow m / z 200.0(35 \%)$ and $m / z 229.0(23 \%)$ for remdesivir, $m / z 292.2 \rightarrow m / z 173.1(24 \%)$ and $m / z 147.1$ (29\%) for GS-
441524 and $m / z 609.3 \rightarrow m / z 206.0(33 \%)$ for remdesivir- ${ }^{13} \mathrm{C}_{6}$. Data acquisition was performed using Xcalibur and LC-Quan softwares (both ThermoFisher).

\section{Method validation procedure}

This method was validated according the EMA guidelines [13].

\section{Selectivity and carry-over}

Six different drug-free blank plasma were analyzed to investigate whether endogenous plasma constituents could interfere at retention times and ion channels of remdesivir, metabolite and IS. Absence of interfering components was accepted if the response was less than $20 \%$ of the LLOQ for the analytes and $5 \%$ for the IS. In order to determine a possible carry-over, a replicate of blank sample was analyzed immediately after the highest CS (upper limit of quantification or ULOQ). Results for blank sample following ULOQ should not be greater than $20 \%$ of the LLOQ and $5 \%$ for the IS.

\section{Calibration curve}

The response of the instrument with regard to the concentration was tested on six different calibration curves analyzed on six different days using the CS previously described. Quantitation was achieved by plotting the peak area ratios of remdesivir and metabolite to the IS versus concentration. The equation showing the lowest and most constant percentage total bias from nominal CS values was considered as the best-fit model. The back calculated concentrations of the CS should be within $\pm 15 \%$ of the nominal value, except for the LLOQ for which it should be within $\pm 20 \%$, and at least $75 \%$ of the CS must fulfill this criterion. Concentration of analytes in the unknown samples was calculated from their peak area ratios and the calibration curve.

\section{LLOQ and limit of detection (LOD)}

The LLOQ was the lowest concentration of remdesivir and GS-441524 which can be measured with accuracy in the range $80-120 \%$ and a precision with a coefficient of variation (CV) of less than $20 \%$. It was validated by analysis of a specific QC sample. Moreover, the signal of analytes for the LLOQ sample had to be at least 5 times the signal of blank sample. The limit of detection was evaluated as the lower concentration with a signal/noise ratio $>3$. 


\section{Accuracy and precision}

The accuracy (reported as percent of the nominal value) and precision (CV) of the assay were determined for the three QC samples and at the LLOQ. For the intraday assay, six replicates of each QC were processed the same day. For the inter-day assay, six replicates of each QC level were processed at three different days. The concentrations obtained were analyzed using analysis of variance (ANOVA), which separated the intraday and interday standard deviation and the corresponding coefficients of variation (CV). An accuracy within the range $85-115 \%$ of the nominal values and a precision with a CV of $\pm 15 \%$ were required.

\section{Matrix effect}

Two procedures (A and B) were performed on six different blank plasma at two concentrations ( 25 and $400 \mu \mathrm{g} / \mathrm{L}$ for remdesivir and 125 and $2000 \mu \mathrm{g} / \mathrm{L}$ for GS-441524) in order to evaluate matrix effect: (A) both compounds and the IS were spiked in $100 \mu \mathrm{L}$ of methanol and directly injected; (B) both compounds and the IS were spiked afterward in blank matrix samples after the precipitation step and recuperation of $100 \mu \mathrm{L}$ of supernatant, and then injected. For both compounds and IS, the matrix factor (MF) was calculated for each different lot of plasma by calculating the ratio of the peak area in the presence of matrix (B) to the peak area in absence of matrix (A). The ISnormalized MF was also calculated by dividing the MF of the analyte by the MF of the IS. The CV of the IS-normalized MF calculated from the six lots of matrix should not be greater than $15 \%$.

\section{Influence of blood collection tube (effect of anticoagulant)}

In order to evaluate compounds stability in container material and anticoagulant, we drawn blood samples in Lithium-heparin (Li-heparin) and sodium fluoride (NaF) tubes from five volunteers in the laboratory and spiked them with $1000 \mu \mathrm{g} / \mathrm{L}$ of remdesivir and $100 \mu \mathrm{g} / \mathrm{L}$ of GS-441524. An aliquot was immediately analyzed for all tubes. Then, we evaluated the stability in whole blood at room temperature and $+4^{\circ} \mathrm{C}$ for $24 \mathrm{~h}$.

\section{Stability}

Stability of stocks and working solutions were evaluated for two weeks. Stability was carried out in Li-heparin and NaF-plasma at room temperature for $24 \mathrm{~h},+4^{\circ} \mathrm{C}$ for $24 \mathrm{~h},-20^{\circ} \mathrm{C}$ for 3 days, and after two freeze/ thaw cycles ( $\mathrm{n}=3$ samples for each study) at the same concentrations used for matrix effect. Autosampler stability of the processed sample at autosampler temperature $\left(8^{\circ} \mathrm{C}\right)$ was evaluated for $24 \mathrm{~h}$ and $48 \mathrm{~h}$. Compounds were considered stable when the differences compared to either freshly prepared samples or concentrations obtained in the first injection for autosampler stability do not exceed $15 \%$.

\section{Pharmacokinetic study}

The proposed analytical method was applied to a pharmacokinetic study in a treated patient by remdesivir for Covid-19. The patient was a woman, 54 years old, height $165 \mathrm{~cm}$ and weight $120 \mathrm{~kg}$ (body mass index=44), with onset of symptoms 11 days before presenting headache, epigastralgia treated by non-steroid anti-inflammatory, zolmitriptan and lamaline ${ }^{\circledast}$ in a peripheric hospital. Her polymerase chain reaction screening of Covid-19 was first negative, with pO2 at $65 \mathrm{~mm}$ $\mathrm{Hg}$ and saturation at $92 \%$, and was treated by ceftriaxone and josamycine. She was then transferred to intensive care unit (ICU) of our universitary hospital 5 days later. She presented bilateral pneumoniae with positive diagnosis of Covid-19 and was intubated and ventilated. Six days later, she was selected for a compassionate use of remdesivir. At that time, she presented Simplified Acute Physiology Score (SAPS) II (measure the severity of disease for patients admitted to ICU) of 33 and Sequential Organ Failure Assessment (SOFA score) of 8. Her treatment was piperacillin/tazobactam, hydroxychloroquine, atracurium, enoxaparin, midazolam, sufentanil, hydroxycortisone, furosemide. She received a loading remdesivir IV dose of $200 \mathrm{mg}$ on day $1 \mathrm{in}$ $60 \mathrm{~min}$. Blood samples were collected in Li-heparin at the following time points, simultaneously to biochemical assessment: before administration $\left(\mathrm{T}_{0}\right)$, then $2 \mathrm{~h}, 4 \mathrm{~h}, 6 \mathrm{~h}, 8 \mathrm{~h}, 10 \mathrm{~h}, 12 \mathrm{~h}, 15 \mathrm{~h}$ and $24 \mathrm{~h}$ after the beginning of perfusion. Tubes were kept at $+4^{\circ} \mathrm{C}$ in the ICU before being brought to the laboratory where they were immediately centrifuged and plasma stored at $-20^{\circ} \mathrm{C}$ until analysis. She received after the loading dose $100 \mathrm{mg}$ once-daily, but died seven days later.

Plasma log concentration-time profiles and PK parameters were calculated using GraphPad Prism V8.3.0 software: $\mathrm{C}_{0}$, the initial concentration for $\mathrm{T}=0$, half-life, and volume of distribution (dose $/ \mathrm{C}_{0}$, monoconpartmental model).

\section{Results}

\section{LC-MS/MS analysis}

The chromatogram obtained for remdesivir $-{ }^{13} \mathrm{C}_{6}$, remdesivir and GS-441524 in a blank sample, the low QC sample and $\mathrm{T}_{4 \mathrm{~h}}$ of the pharmacokinetic of the patient were shown in Figure 2. The retention time was $1.69 \mathrm{~min}$ for metabolite, 2.41 and $2.42 \mathrm{~min}$ for remdesivir and IS.

\section{Method validation}

\section{Selectivity, carry over}

No interference was observed from the six different blank matrices on the retention times and ion channel of both compounds and IS (Figure 2A). A signal less than $2 \%$ of the signal observed at the LLOQ was observed at the retention time of all compounds on the blank reinjected after the highest calibration standard. There was no significant carry-over.

\section{Linearity}

A linear regression analysis with weighing factor $(1 / x)$ was the best fitting model as determined by bias analysis in the $1-5000 \mu \mathrm{g} / \mathrm{L}$ range for remdesivir and $5-2500 \mu \mathrm{g} / \mathrm{L}$ range 

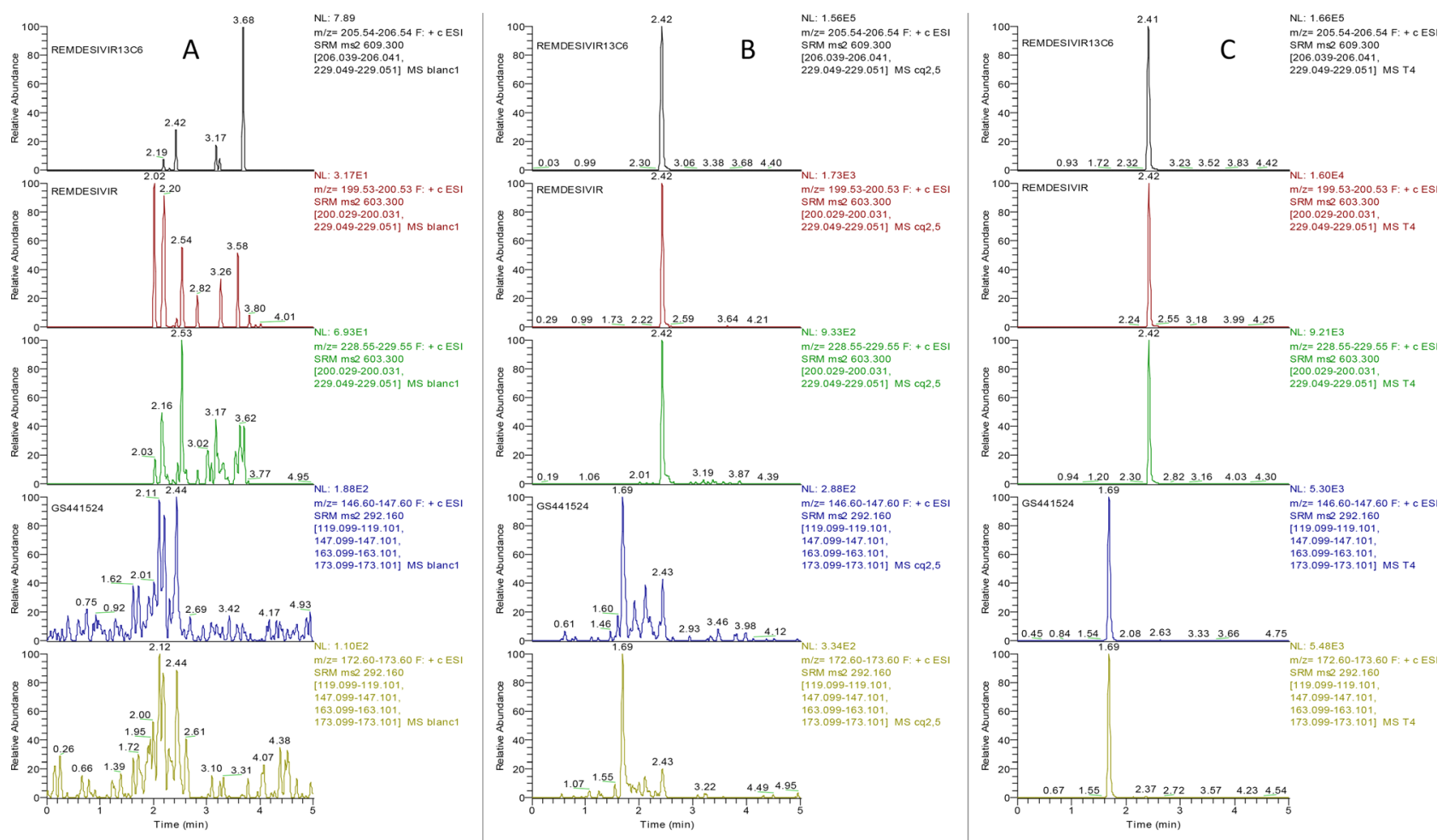

Figure 2: Liquid chromatography coupled to tandem mass spectrometry (LC-MS/MS) chromatograms of internal standard (IS) (upper graph), remdesivir (medium graphs), and GS-441524 (lower graphs) of a blank plasma sample (A), low quality control (QC) sample at $2.5 \mu \mathrm{g} / \mathrm{L} \mathrm{of}$ remdesivir and $12.5 \mu \mathrm{g} / \mathrm{L}$ of GS-441524 (B) and plasma of the treated patient $\left(\mathrm{H}_{4}\right.$ after beginning of infusion) with $29 \mu \mathrm{g} / \mathrm{L}$ of remdesivir and $265 \mu \mathrm{g} / \mathrm{L}$ of GS-441524 (C).

for GS-441524. The equations for the curves $(n=6)$ were: $y=(0.00301 / x)-0.0000643$ for remdesivir and $y=(0.00015 /$ $x)-0.0000448$ for GS-441524. Coefficient of determination $r^{2}$ were $=0.998( \pm 0.001)$ and $0.997( \pm 0.001)$, respectively. Interday CV ranged from 1.7 to $13.4 \%$ and bias from -3.4 to $3.7 \%$ for the back-calculated concentrations of the CS for remdesivir, and 2.7 to $10.2 \%$ and -5.7 to $6.4 \%$ for GS441524, respectively. $100 \%$ of the CS fulfilled the criterion for validation for remdesivir and 93\% for GS-441524.

\section{Limit of quantification (LLOQ) and detection (LOD)}

The LLOQ was set at $1 \mu \mathrm{g} / \mathrm{L}$ for remdesivir and $5 \mu \mathrm{g} / \mathrm{L}$ for GS441524, with their corresponding accuracy and precision shown in Table 1. The signal-to-noise ratio was greater than five in both cases. The LODs were estimated at concentration of $0.3 \mu \mathrm{g} / \mathrm{L}$ and $2 \mu \mathrm{g} / \mathrm{L}$, respectively.

\section{Accuracy and precision}

Intra-day and inter-day precision and accuracy of QC samples were summarized in Table 1. All values were in the [89.6$110.2 \%$ ] range for accuracy and lower than $14.7 \%$ for precision.

\section{Matrix effect}

Matrix effect values were reported in Table 2. For remdesivir, GS-441524 and IS, MF was similar, ranging from 72 to $84 \%$. The IS-normalized MF was in the [93-107\%] range, with CV obtained in the six lots of plasma $<9 \%$ for remdesivir and its metabolite.

\section{Influence of blood collection tube (effect of anticoagulant)}

The influence of blood collection tubes between Li-heparin and $\mathrm{NaF}$ on whole blood stability was presented in Table 3. Remdesivir and GS-441524 were stable in whole blood stored at $+4^{\circ} \mathrm{C}$ for $24 \mathrm{~h}$ but not at ambient temperature.

\section{Stability}

Stocks solutions of the three compounds and working solutions were stable for at least two weeks. Stability in plasma in different storage conditions were shown in Table 3. Stability for remdesivir was adequate in NaF-plasma when frozen at $-20{ }^{\circ} \mathrm{C}$. On Li-heparin-plasma, a $50-60 \%$ 
Table 1: Validation settings of remdesivir and GS-441524.

\begin{tabular}{cclrr}
\hline & & Remdesivir & GS-441524 \\
\hline Accuracy, \% & Intra-assay & LLOQ & 97.7 & 101.0 \\
& & Low & 100.3 & 94.8 \\
& & Medium & 108.7 & 99.7 \\
& High & 88.9 & 103.5 \\
& \multirow{2}{*}{ Inter-assay } & LLOQ & 100.4 & 98.4 \\
& & Low & 98.6 & 99.1 \\
& & Medium & 110.2 & 101.7 \\
& High & 89.6 & 104.1 \\
Precision & Intra-assay & LLOQ & 7.3 & 8.2 \\
(CV, \%) & & Low & 4.6 & 3.9 \\
& & Medium & 2.8 & 4.1 \\
& & High & 2.5 & 5.3 \\
& Inter-assay & LLOQ & 5.6 & 12.7 \\
& & Low & 11.9 & 14.7 \\
& & Medium & 5.2 & 4.2 \\
& & High & 2.6 & 3.2 \\
\hline
\end{tabular}

$\mathrm{CV}$, coefficient of variation; QC levels, remdesivir: LLOQ, $1 \mu \mathrm{g} / \mathrm{L}$, Low, $2.5 \mu \mathrm{g} / \mathrm{L}$, medium, $400 \mu \mathrm{g} / \mathrm{L}$, high, $4000 \mu \mathrm{g} / \mathrm{L}$; GS-441524, LLOQ, $5 \mu \mathrm{g} / \mathrm{L}$, low, $12.5 \mu \mathrm{g} / \mathrm{L}$, medium, $125 \mu \mathrm{g} / \mathrm{L}$, high, $2000 \mu \mathrm{g} / \mathrm{L}$.

Table 2: Accuracies and precisions of lower limit of quantification (LLOQ) and quality control (QC) samples.

\begin{tabular}{lrrrr}
\hline & & MF & \multicolumn{2}{c}{ IS-normalized MF } \\
\cline { 5 - 6 } & & $\%$ & $\%$ & CV, \% \\
\hline Remdesivir, $\mu \mathrm{g} / \mathrm{L}$ & 25 & 78 & 101 & 2.2 \\
& 400 & 84 & 107 & 3.2 \\
GS-441524, $\mu \mathrm{g} / \mathrm{L}$ & 125 & 72 & 93 & 9.0 \\
& 2000 & 84 & 107 & 5.8 \\
El, $\mu \mathrm{g} / \mathrm{L}$ & 300 & 76 & 100 & - \\
\hline
\end{tabular}

MF, matrix factor (ratio of the peak area in the presence of matrix to the peak area in absence of matrix); IS-normalized MF, ratio of MF of the analyte by the MF of the IS; CV calculated from six different lots of plasma.

decrease was observed even if plasma was frozen at $-20^{\circ} \mathrm{C}$. GS-441524 is stable in both plasma when frozen at $-20^{\circ} \mathrm{C}$. However, after two frozen/thaw cycles, GS-441524 appeared to increase in Li-heparin-plasma for the high concentration $(2000 \mu \mathrm{g} / \mathrm{L})$.

Autosampler stability of the processed sample at autosampler temperature $\left(8^{\circ} \mathrm{C}\right)$ was confirmed for $24 \mathrm{~h}$ and $48 \mathrm{~h}$ (difference $<5 \%$ ).

\section{Pharmacokinetic study}

The plasma log concentration-time profiles of remdesivir and GS-441524 from the Covid-19 treated patient who received intravenous remdesivir are shown in Figure 3. Plasma concentration of remdesivir was found at $150 \mu \mathrm{g} / \mathrm{L}$
$2 \mathrm{~h}$ after the beginning of perfusion, followed by a rapid decrease. After $10 \mathrm{~h}$, concentrations were under the LLOQ. Half-life was evaluated in this patient at $0.8 \mathrm{~h} . \mathrm{C}_{0}$ was evaluated at $800 \mu \mathrm{g} / \mathrm{L}$, leading to a volume of distribution of $200 \mathrm{~L}$ for remdesivir in this patient. GS-441524 was present at $\mathrm{H}_{2}$ at $300 \mu \mathrm{g} / \mathrm{L}$ and showed a slow concentration decrease during $24 \mathrm{~h}$ (concentration of $120 \mu \mathrm{g} / \mathrm{L}$ at $\mathrm{H}_{24}$ ). Half-life was evaluated at $12 \mathrm{~h}$.

\section{Discussion}

We have developed and fully validated according to the EMA guidelines a new method for the measurement of plasma concentrations of remdesivir and its active metabolite, GS-441524. This method was successfully applied to a pharmacokinetic study in a patient suffering from Covid-19.

We used deuterated remdesivir (remdesivir- ${ }^{13} \mathrm{C}_{6}$ ) as IS. It is always of importance of selecting the most suitable IS when validating a LC-MS/MS method. It is the best practice to use a deuterated analog of the analyte being measured as they have similar chemical properties, ionization response in electrospray ionization mass spectrometry and the same chromatographic retention time. The deuterated IS co-elute with the analyte to be quantified and contain enough mass increase to show a signal outside the natural mass distribution of the analyte (Figure 2). Moreover, deuterated IS allow to compensate matrix effect, which was relatively low for remdesivir $(\mathrm{MF}=78-84 \%)$. For the metabolite, deuterated GS-441524 was not commercially available, but matrix effect of the metabolite $(\mathrm{MF}=72-84 \%)$ was similar to that of remdesivir, and the use of remdesivir ${ }^{13} \mathrm{C}_{6}$ as IS for GS-441524 allow to compensate this slow matrix effect (IS-normalized $\mathrm{MF}=93-107 \%$, with $\mathrm{CV} \leq 9.0$ ).

According to EMA guidelines [13], the study of dilution integrity should also be evaluated, but it was considered here unnecessary considering the high ULOQ validated in calibration curves ( $5000 \mu \mathrm{g} / \mathrm{L}$ for remdesivir and $2500 \mu \mathrm{g} / \mathrm{L}$ for GS).

The LLOQs of remdesivir and GS-441524 used in our method are less than $5 \%$ of the $\mathrm{C}_{\max }$ as required [12], and appeared enough when looking at the pharmacokinetics obtained in the treated patient and the $\mathrm{EC}_{50}$ of remdesivir on SARS-CoV-2 $[5,6]$. The data of accuracies and precisions of QCs samples indicated that the present method is accurate, precise and reproducible for quantification of remdesivir and its active metabolite throughout a wide dynamic range.

Influence of blood collection tube has shown that $\mathrm{Li}$ heparin collection tubes are not suitable if there are not stored at $4^{\circ} \mathrm{C}$ rapidly after sampling. When stored at room temperature for $24 \mathrm{~h}$, we observed a $74 \%$ decrease in 
Table 3: Influence of blood collection tube and stability in plasma of remdesivir and GS-441524.

\begin{tabular}{|c|c|c|c|c|c|c|}
\hline & & & $\begin{array}{r}\text { Ambient temperature } \\
\text { for } 24 \mathrm{~h}\end{array}$ & $4^{\circ} \mathrm{C}$ for $24 \mathrm{~h}$ & $-20^{\circ} \mathrm{C}$ for 3 days & 2 frozen/thaw cycles \\
\hline \multirow[t]{6}{*}{ Remdesivir } & Li-heparin & Whole blood & 26 & 92 & - & - \\
\hline & & P $25 \mu \mathrm{g} / \mathrm{L}$ & 3 & 40 & 41 & 35 \\
\hline & & $\mathrm{P} 400 \mu \mathrm{g} / \mathrm{L}$ & 5 & 54 & 49 & 43 \\
\hline & $\mathrm{NaF}$ & Whole blood & 87 & 97 & - & - \\
\hline & & P $25 \mu \mathrm{g} / \mathrm{L}$ & 68 & 89 & 100 & 87 \\
\hline & & $\mathrm{P} 400 \mu \mathrm{g} / \mathrm{L}$ & 69 & 92 & 101 & 96 \\
\hline \multirow[t]{6}{*}{ GS-441524 } & Li-heparin & Whole blood & 147 & 101 & - & - \\
\hline & & P $125 \mu \mathrm{g} / \mathrm{L}$ & 67 & 77 & 91 & 87 \\
\hline & & P $2000 \mu \mathrm{g} / \mathrm{L}$ & 87 & 89 & 116 & 147 \\
\hline & $\mathrm{NaF}$ & Whole blood & 101 & 103 & - & - \\
\hline & & P $125 \mu \mathrm{g} / \mathrm{L}$ & 100 & 83 & 101 & 97 \\
\hline & & $\mathrm{P} 2000 \mu \mathrm{g} / \mathrm{L}$ & 89 & 79 & 98 & 96 \\
\hline
\end{tabular}

All results in \% of initial concentration. P, Li-heparin plasma or NaF-plasma. Concentration in whole blood: remdesivir=1000 $\mu \mathrm{g} / \mathrm{L}$, GS-441524=100 $\mu \mathrm{g} / \mathrm{L}$.

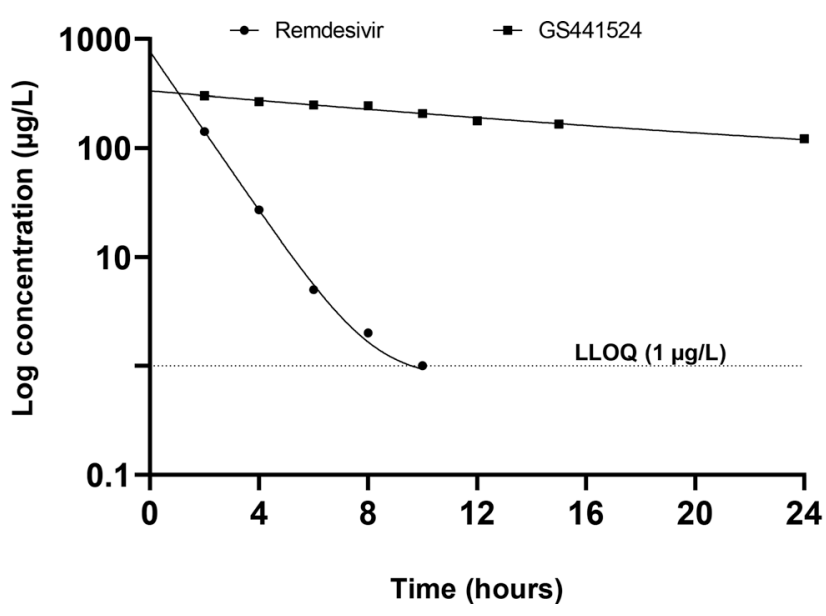

Figure 3: Pharmacokinetics of remdesivir and GS-441524 observed in the treated patient.

remdesivir with a simultaneous increase in the metabolite, probably due to the degradation of remdesivir. This important degradation was also seen in Li-heparin-plasma stored at room temperature (more than $90 \%$ of decrease) while it is weaker in the NaF-plasma (around 30\% of decrease). The difference is due to the inhibition of enzymes like esterases by fluorure of sodium, leading to a much higher stability in NaF tube, which should be used when sampling patients for remdesivir therapeutic drug monitoring or pharmacokinetic studies.

Unfortunately, the patient treated here was sampled before this stability study, and Li-heparin tubes were used. Whole blood samples were kept at $+4{ }^{\circ} \mathrm{C}$ before being brought to the laboratory, but the plasma was immediately frozen on arrival at the laboratory and it can be assumed that around $50 \%$ of remdesivir was lost according to our stability results, with conservation of the metabolite. As the loss of remdesivir is similar between low ( $41 \%$ at $25 \mu \mathrm{g} / \mathrm{L})$ and higher concentration $(49 \%$ at $400 \mu \mathrm{g} / \mathrm{L})$, the half-life of remdesivir should not be modified (stability of the slope of the concentration curve). Stability in post mortem whole blood has not been tested. However, since esterases cease their activity after death, sampling in $\mathrm{NaF}$ tubes at autopsy must allow to determine the post mortem concentrations of the drugs.

Our patient received a loading IV dose of $200 \mathrm{mg}$ in $60 \mathrm{~min}$, and considering the absence of data from Covid-19 patients, resuscitators from ICU asked for a therapeutic drug monitoring of the drug and its active metabolite.

In the literature, the only data available are those of the report of Gilead. $\mathrm{C}_{\max }$ of remdesivir was found at $2280 \mu \mathrm{g} / \mathrm{L}$ in eight subjects ( $\mathrm{CV}=30.0 \%)$ after a single $2 \mathrm{~h} \mathrm{IV}$ infusion of remdesivir $150 \mathrm{mg}$, and at $4421.3 \mu \mathrm{g} / \mathrm{L}$ in eight subjects $(\mathrm{CV}=16.0 \%)$ after a dose of $225 \mathrm{mg}$. $\mathrm{C}_{\max }$ following 30-minutes IV infusion of remdesivir loading-dose of $200 \mathrm{mg}$ in eight subjects was found at $5400 \mu \mathrm{g} / \mathrm{L}(\mathrm{CV}=20.3 \%)$ on day one, and $2610 \mu \mathrm{g} / \mathrm{L}(\mathrm{CV}=12.7 \%)$ on day 5 in seven subjects after the loading-dose followed by $100 \mathrm{mg}$ daily for four days [12].

$\mathrm{C}_{\max }\left(\mathrm{C}_{0}\right)$ in the patient treated here was evaluated at $800 \mu \mathrm{g} / \mathrm{L}$. Considering the probable degradation of remdesivir, the concentration should be probably two-timing more elevated. However, Gilead studies were realized in healthy subjects, which are different from Covid-19 patients hospitalized in ICU. Our patient was in a critical state when she was treated, with SAPS II score of 33 and SOFA score of 8 . The volume of distribution was found very important $(200 \mathrm{~L})$ in our patient suffering from morbid obesity (BMI=44), which is another difference with healthy subject. Half-life was found 
at $0.8 \mathrm{~h}$, very closed to that described in healthy subjects (0.89 to $0.98 \mathrm{~h}$ ) [12]. GS-441524, which is the active metabolite of remdesivir, appeared rapidly in plasma since it was already at its maximal concentration at $\mathrm{H}_{2}$, consistent with metabolism by hydrolases. Its half-life is longer than remdesivir, around $12 \mathrm{~h}$ in our patient and around $24 \mathrm{~h}$ in healthy subject [12]. This long half-life of the active metabolite allows the use of remdesivir infusion once-daily despite the short half-life of remdesivir itself.

\section{Conclusions}

To our knowledge, this is the first method of quantification of remdesivir and its active metabolite in plasma with application to a treated patient. A small quantity of plasma is required, making the method also suitable for children plasma monitoring of the drugs. Sample preparation requirements are minimal and short analytical time enables high throughput analysis. Stability was evaluated revealing that blood sampling should be drawn in $\mathrm{NaF}$ tubes. This method should be useful for the pharmacokinetic/pharmacodynamic relationship studies of these compounds in Covid-19 pandemic.

Research funding: None declared.

Author contributions: All authors have accepted responsibility for the entire content of this manuscript and approved its submission.

Competing interests: Authors state no conflict of interest. Informed consent: Informed consent was obtained from all individuals included in this study.

\section{References}

1. Kakodkar P, Kaka N, Baig MN. A comprehensive literature review on the clinical presentation, and management of the pandemic coronavirus disease 2019 (COVID-19). Cureus 2020;12:e7560.
2. Sanders JM, Monogue ML, Jodlowski TZ, Cutrell JB. Pharmacologic treatments for coronavirus disease 2019 (COVID-19): a review. JAMA 2020;323:1824-36.

3. Warren TK, Jordan R, Lo MK, Ray AS, Mackman RL, Soloveva V, et al. Therapeutic efficacy of the small molecule GS-5734 against Ebola virus in rhesus monkeys. Nature 2016;531:381-5.

4. Sheahan TP, Sims AC, Leist SR, Schäfer A, Won J, Brown AJ, et al. Comparative therapeutic efficacy of remdesivir and combination lopinavir, ritonavir, and interferon beta against MERS-CoV. Nat Commun 2020;11:222.

5. Choy KT, Yin-Lam Wong A, Kaewpreedee P, Sia SF, Chen D, Yan Hui $\mathrm{KP}$, et al. Remdesivir, lopinavir, emetine, and homoharringtonine inhibit SARS-CoV-2 replication in vitro. Antiviral Res 2020;178: 104786.

6. Wang M, Cao R, Zhang L, Yang X, Liu J, Xu M, et al. Remdesivir and chloroquine effectively inhibit the recently emerged novel coronavirus (2019-nCoV) in vitro. Cell Res 2020;30:269-71.

7. Agostini ML, Andres EL, Sims AC, Graham RL, Sheahan TP, Lu X, et al. Coronavirus susceptibility to the antiviral remdesivir (GS5734 ) is mediated by the viral polymerase and the proofreading exoribonuclease. MBio 2018;9:e00221-18.

8. Gordon CJ, Tchesnokov EP, Feng JY, Porter DP, Götte M. The antiviral compound remdesivir potently inhibits RNA-dependent RNA polymerase from Middle East respiratory syndrome coronavirus. J Biol Chem 2020;295:4773-9.

9. Amirian ES, Levy JK. Current knowledge about the antivirals remdesivir (GS-5734) and GS-441524 as therapeutic options for coronaviruses. One Health 2020;9:100128.

10. Grein J, Ohmagari N, Shin D, Diaz G, Asperges E, Castagna A, et al. Compassionate use of remdesivir for patients with severe Covid-19. N Engl J Med 2020. https://doi.org/10.1056/ NEJMoa2007016.

11. Kalil AC. Treating COVID-19-off-label drug use, compassionate use, and randomized clinical trials during pandemics. JAMA 2020; 323:1897-8

12. European Medicines Agency, Science Medicines Health. Report on summary on compassionate use remdesivir. Gilead; 2020. Available from: https://www.ema.europa.eu/ en/documents/other/summary-compassionate-useremdesivir-gilead_en.pdf.

13. European Medicines Agency. Guideline on bioanalytical method validation. European Medicines Agency; 2011 Available from: https://www.ema.europa.eu/en/documents/scientificguideline/guideline-bioanalytical-method-validation_en.pdf. 